Available online on 15.07.2020 at http://ujpr.org
Universal Journal of Pharmaceutical Research
An International Peer Reviewed Journal
Open access to Pharmaceutical research

\title{
PHYTOCHEMICAL PROFILE WITH ANTI-TUMOR ACTIVITY ESTIMATION OF CRUDE EXTRACT, ESSENTIAL OIL AND D-LIMONENE FROM CITRUS AURANTIUM L. AGAINST EHRLICH CARCINOMA

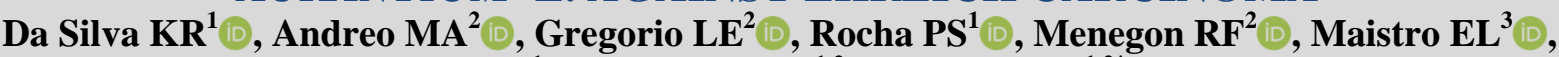

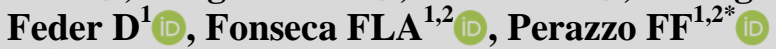 \\ ${ }^{\prime}$ ABC Medical School, Santo Andre, São Paulo, Brazil. \\ ${ }^{2}$ Institute de Environmental, Chemistry and Pharmaceutical Sciences, UNIFESP, Diadema, SP, Brazil. \\ ${ }^{3}$ Departament de Phonoaudiology, Faculty of Philosophy and Sciences, UNESP, Marília, SP, Brazil.
}

\section{ABSTRACT}

Objective: Plant based drugs have been a solution in the search for more cost-effective and less harmful drugs for the treatment of neoplasia. Citrus aurantium L. (Rutaceae) is abundant in Brazil and D-limonene, a monoterpene used in the prevention and treatment of neoplasia, was identified as a major compound in the oil of this specie. Objective of current study includes estimation of anti-tumor activity of Citrus aurantium L. (Rutaceae) (crude extract, essential oil and D-limonene) against Ehrlich carcinoma, as well as their phytochemical evaluation (D-limonene and essential oil).

Methods: There was a randomized non-clinical trial in which were used adult male mice (Balb-C). Four groups of animals were used having 6 numbers of animal in each group. All groups were inoculated with the Ehrlich tumor and then received the treatment (control, crude extract, essential oil and D-limonene) by oral route daily (28 day treatment). Essential oil was obtained by hydrodistillation and analyzed by the means of GC (Gas Chromatography) that was attached to mass spectrometry. In last of the observations hemogram was obtained.

Results: Animals treated with the essential oil has shown no significant difference compared to the group treated with Dlimonene. The group treated with crude extract had a growth inhibition close to the essential oil and D-limonene groups.

Conclusion: It's concluded that the essential oil and the crude extract of Citrus aurantium, L. (Rutaceae) can become therapeutic agents because of their anti-tumor activity with no toxicity to the blood cells and have low cost of production. Further studies are necessary, so they can be used in the treatment of neoplasia in humans. The chromatographic and spectrometric analyzes indicated the presence of other components in smaller amounts in the essential oil, which suggests that they could have a synergic activity to the D-limonene.

Keywords: cancer, Citrus aurantium L, D-limonene, Ehrlich carcinoma, Rutaceae, spectrometry.

Article Info: Received 17 May 2020; Revised 12 June; Accepted 5 July, Available online 15 July 2020

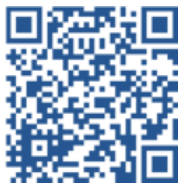
Cite this article-

Da Silva KR, Andreo MA, Gregorio LE, Rocha PS, Menegon RF, Maistro EL, Feder D, Fonseca FLA, Perazzo FF. Phytochemical profile with anti-tumor activity estimation of crude extract, essential oil and D-limonene from Citrus aurantium L. against Ehrlich carcinoma. Universal Journal of Pharmaceutical Research 2020; 5(3):27-33.

DOI: https://doi.org/10.22270/ujpr.v5i3.412

Address for Correspondence

Fabio Ferreira Perazzo, Rua São Nicolau, 210, Centro, Diadema, São Paulo, Brazil, 09961-400, Tel: +55 11 4004-0500, E-mail: ffperazzo@unifesp.br

\section{INTRODUCTION}

Plant based drugs have been a solution in the search for more cost-effective and less harmful drugs for the treatment of neoplasia. Several species originated medicines such as Taxus brevifolia $\left(\right.$ Paclitaxel $\left.^{\circledR}\right)$, Catharanthus roseus (vincristine and vimblastine), Curcuma longa (curcumin) and others. Citrus aurantium L. belongs to Rutaceae family, is familiar as orange, is a traditional fruit abundant in Brazil. From it peels, D-limonene, a chemical marker was identified. This compound is a monoterpene used in the prevention and treatment of neoplasia ${ }^{1}$. Limonene is a cheap, effective and promising compound with a broad spectrum of anticancer activity ${ }^{1,2}$. Moreover, the anticancer of orange essential oil and other compounds present, were investigated in cancer cell lines A549 (human lung) and 22RV-1 (prostate). The essential oil, comprised mainly with D-limonene (74.6\%) has potential to affect positively the proliferation and cells line inhibition ${ }^{2}$. The constituents of the essential oils are originated by the mevalonic acid pathway. Preferentially, monoterpenes and sesquiterpenes are synthetized (hydrocarbons having $\left(\mathrm{C}_{5} \mathrm{H}_{8}\right)_{\mathrm{n}}$ formula), known as isoprene are oxygenated compounds. These 
are obtained from hydrocarbons like oxides, phenols, ethers, aldehydes, esters, ketones and alcohols. There are several activities reported for this class, like as antibacterial, antifungal, antiviral and antioxidant properties $^{3}$. Genus Citrus includes species of oranges, grapes, limes, lemons, and tangerines. As far as genus Citrus is concerned in Brazil, it is a commercial fruit's crop. Since two decades ago, D-limonene is popularly known to possess anticancer activities and it exists in varieties of fruits and vegetables ${ }^{4}$. However at present many researchers are attracted towards it for its impressive therapeutic potential. As far as structure of Limonene is concerned it has two isoprene units that have $>90 \%$ essential oil. It induce apoptosis on the tumor cells and has shown potential for the treatment of skin, fore stomach, lung and liver cancer ${ }^{5,6}$. It has been demonstrated to induce apoptosis on tumor cells ${ }^{6}$. Perillyl alcohol, that is a hydroxylated limonene analog has shown chemopreventive activity. It has shown its chemotherapeutic potential against cancer of colon, pancreas, mammary gland and liver in rodent ${ }^{7}$.

Limonene consist of different metabolites, main are (+)- and (-)-trans-carveol (6-hydroxylation product), $(+)$ - and (-)-perillyl alcohol (7-hydroxylation product by CYP2C9 and CYP2C19 cytochromes in human liver microsomes ${ }^{8}$ ). In previous studies, perillyl alcohol's enantiomers have been investigated for their chemotherapeutic potential. They are detected as alternative therapeutic options in some CNS neoplasms and solid tumors as in gliomas treatment ${ }^{9}$. Perillyl alcohol and limonene metabolites have cytotoxic potential because of several properties like their hyperthermia inducing effects, RAS pathways, antiangiogenic activities and negative apoptosis regulations ${ }^{10}$. The study of orange oil, limonene and extracts has shown an interesting effect of these compounds upon cancer and several illnesses associated to antioxidant activity. Some enzymes activity was analyzed showing increase of GST (glutathione-S- transferase), GSH (glutathione content) and LPO (lipid peroxidation), that favor their antitumor potential $^{11}$. Considering the exposed above, it is important to study all possibilities associated to orange oil and cancer, once this is a cheap product, with high production in Brazil and well seeing all over the world as a promising agent in this filed. The objective of current study was to estimate the anti-tumor potential of essential oil, crude extract and D-limonene against Ehrlich carcinoma as well as the phytochemical analyses of the essential oil and D-limonene of $C$. aurantium and the comparison among these products.

\section{MATERIALS AND METHODS \\ Essential oil GC-MS (gas chromatography-mass spectrometry)}

Shimadzu gas chromatograph (GC-2012) was used for the GC analysis, it was equipped with flame ionization detector and DB-5 (fused silica) column having film thickness $0.25 \mu \mathrm{m}, 30 \mathrm{~m} \times 0.25 \mathrm{~mm}$, and $1: 25$ split ration. As far as GC setting were concerned, $40^{\circ} \mathrm{C}$ initial oven temperature was maintained for $1 \mathrm{~min}$ and elevated up to $250^{\circ} \mathrm{C}$ at the rate of $5^{\circ} \mathrm{C} / \mathrm{min}$. Injector temperature was kept $250^{\circ} \mathrm{C}$ and detector temperature was kept $23^{\circ} \mathrm{C}$. Helium was used as carrier gas having flow rate of $1.37 \mathrm{ml} / \mathrm{min}$. GC-MS was done by the means of Agilent Technology 5973, having mass selective detector that was attached with Shimadzu GC-2012 plus gas chromatograph. C. aurantium oil and Dlimonene was analyzed by means of DB-5 (Fused silica) with the same mentioned column and temperature programmed. The MS was operated at ionization energy from 10 to $200 \mathrm{EV}$. By the means of FID (Flame Ionization Detector) peak areas, quantitative data were collected ${ }^{12}$.

\section{Animals}

Mice were obtained from the Central Biotery of FMABC. Ethical approval was taken from Federal University of São Paulo Animal Ethics Committee (CEUA\#415527) to conduct all animals related testing. Mice (Balb-C, 20-28 g) of 8 weeks of age were used for the experiment and were kept in polyacrylic cages. The animals were grouped in three per cage. Standard laboratory conditions were maintained having temperature $\left(20 \pm 2^{\circ} \mathrm{C}\right)$, and relative humidity $(55 \pm 5 \%)$ and 12/12 h dark/light cycle. Water and standard dry pellet diet were administered ad libitum.

\section{Ehrlich tumor model}

From the donor mice (Balb-C) having 20-28 g body weight, EAC cells were obtained by the means of sterilized disposable syringe and placed in isotonic saline. As estimated by the trypan blue exclusion assay, the cells viability was found to be $99 \%$. Fixed number of viable cells $(0.2 \mathrm{ml}$ EAC cells with $5 \times 10^{5}$ cells/mouse), were used to assess Ehrlich tumor's solid mass. Cells were intraperitoneally inoculated and kept for 28 days in order to grow the tumor.

\section{Treatment schedule}

Seven days after the inoculation of the Ehrlich cells, the treatments have started. The animals $(n=24)$ were placed in four groups, having 6 mice per group. Daily, treatment was given orally by gavage as below-

Group I (control group): given $0.3 \mathrm{ml}$, saline solution (0.9\%).

Group II: Treated with $0.3 \%$ of crude extract of $C$. aurantium diluted in $0.50 \mathrm{ml}$ of $0.9 \%$ saline solution.

Group III: treated with $0.3 \mathrm{ml}$ of essential oil from $C$. aurantium

Group IV: treated with $0.3 \mathrm{ml}$ of D-limonene diluted in $0.50 \mathrm{ml}$ of $0.9 \%$ saline solution.

In order to measure the tumor growth, the animals were measured weekly with a digital pachymeter. After 28 days of experiment, mice were sacrificed by cervical decapitation. Blood was collected and storage in EDTA tubes for hemogram analyses. The tumor mass were weighed, storaged and frozen in liquid nitrogen.

\section{Statistical analysis}

In present work data distribution was done by the means of Shapiro-Wilk method. For the correlation regarding body size and body weight between moments in the groups was used the Spearman test. The difference regarding body weight and size in the initial and final moments among groups was analyzed using the Kruskall-Wallis test was used. Experiment was performed by the means of software (Stat 11) ${ }^{13}$. 


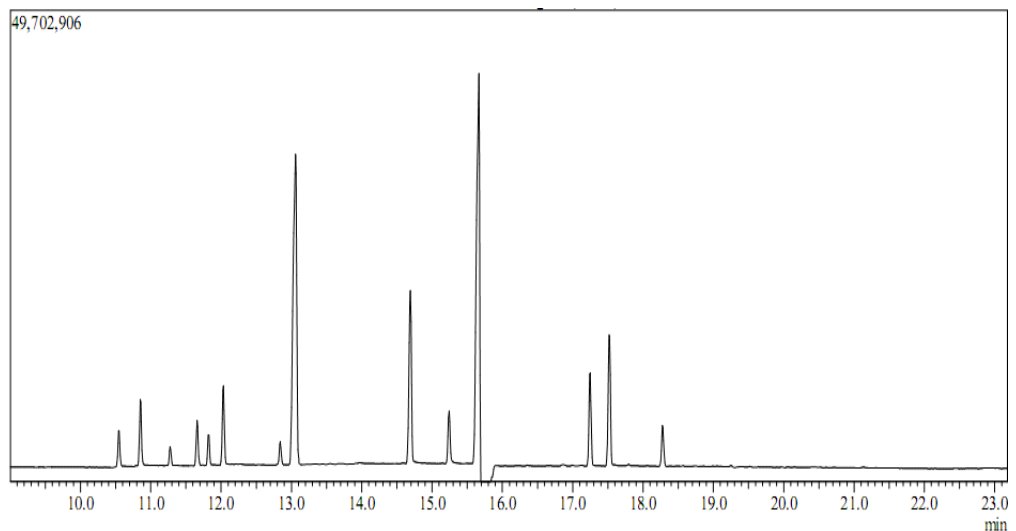

Figure 1: C. aurantium essential oil GC-MS profile.

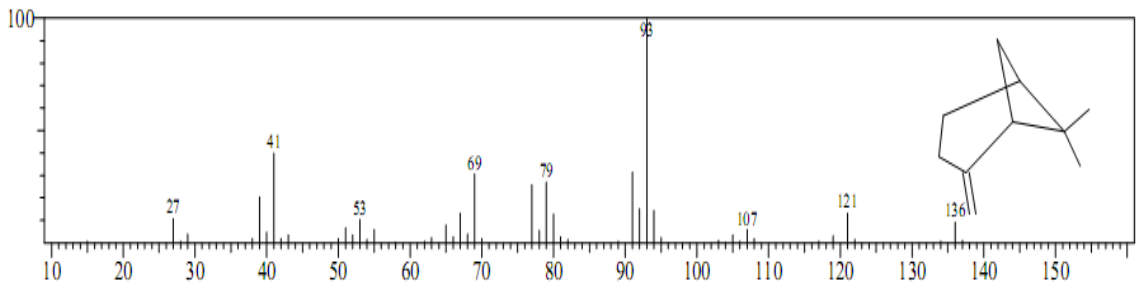

Figure 2: $\beta$-pinene GC-MS profile.

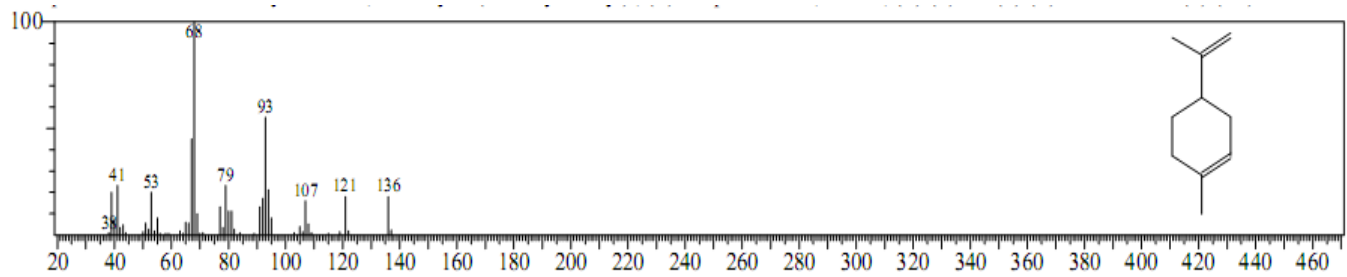

Figure 3: D-limonene GC-MS profile.

\section{RESULTS AND DISCUSSION}

Since ancient time, products of natural origin have long history to be used in the traditional medicines for the treatment of various diseases, and due to it, many researchers are working on these since few decades. Herbal plants have volatile liquids and essential oils that have aromatic properties and used as the ingredients in different herbal formulations. From dietary sources, Perillyl alcohol is obtained and have potential for the treatment of cancer, suppression of tumor growth and regression ${ }^{14}$. Peels of the citrus fruits is considered as the waste product in the companies engaged in juice products preparations. Since many years, these waste peels are also creating problems for the environment related to green ecology policies. To solve such problems, there is one well known approach, is the utilization of the yeasts or strains of bacteria for the transformation of these (monoterpene). Many fruits and vegetables contail Limonene (monoterpene), it consist of two isoprene units, having $>90 \%$ essential oil. However, nearly two decades ago, the anticancer potential of D-limonene was estimated, but very recently many researchers are attracted towards it to develop medicines for the treatment of cancer ${ }^{4}$. Qualitative and quantitative evaluation of chemical constituents was done by the means of GCMS. Total 54 components were detected in essential oil and 44 components were detected in the extracts.

D-limonene was the main components in all cultivars in the range of $73.9-97 \%$. Nerol, geraniol and linalool were present in the discrete amount. Cluster analysis of essential oils has shown some degree of affinity in between same type cultivars.

Table 1: Lifespan and weighs of the animals at the beginning and end of the experiment.

\begin{tabular}{|c|c|c|c|c|}
\hline & Animal & Lifespam & $\begin{array}{l}\text { Initial } \\
\text { weight }\end{array}$ & $\begin{array}{l}\text { Final } \\
\text { weight }\end{array}$ \\
\hline \multirow{6}{*}{ 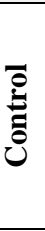 } & $\mathrm{C} 1$ & 28 & 26 & 28 \\
\hline & C2 & 28 & 24 & 28 \\
\hline & C3 & 28 & 24 & 24 \\
\hline & $\mathrm{C} 4$ & 28 & 24 & 26 \\
\hline & C5 & 28 & 22 & 26 \\
\hline & C6 & 28 & 22 & 28 \\
\hline \multirow{6}{*}{ 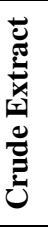 } & $\mathrm{C} 1$ & 28 & 28 & 30 \\
\hline & $\mathrm{C} 2$ & 28 & 26 & 20 \\
\hline & $\mathrm{C} 3$ & 28 & 26 & 28 \\
\hline & $\mathrm{C} 4$ & 28 & 26 & 28 \\
\hline & C5 & 28 & 24 & 28 \\
\hline & C6 & 28 & 24 & 30 \\
\hline \multirow{6}{*}{ 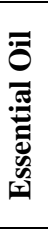 } & $\mathrm{C} 1$ & 28 & 24 & 26 \\
\hline & $\mathrm{C} 2$ & 28 & 24 & 26 \\
\hline & $\mathrm{C} 3$ & 28 & 24 & 26 \\
\hline & $\mathrm{C} 4$ & 28 & 26 & 28 \\
\hline & C5 & 28 & 28 & 30 \\
\hline & C6 & 28 & 26 & 20 \\
\hline \multirow{6}{*}{ 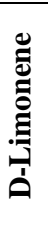 } & $\mathrm{C} 1$ & 28 & 28 & 32 \\
\hline & $\mathrm{C} 2$ & 28 & 24 & 26 \\
\hline & $\mathrm{C} 3$ & 28 & 26 & 30 \\
\hline & $\mathrm{C} 4$ & 28 & 26 & 28 \\
\hline & C5 & 28 & 24 & 26 \\
\hline & C6 & 28 & 26 & 28 \\
\hline
\end{tabular}




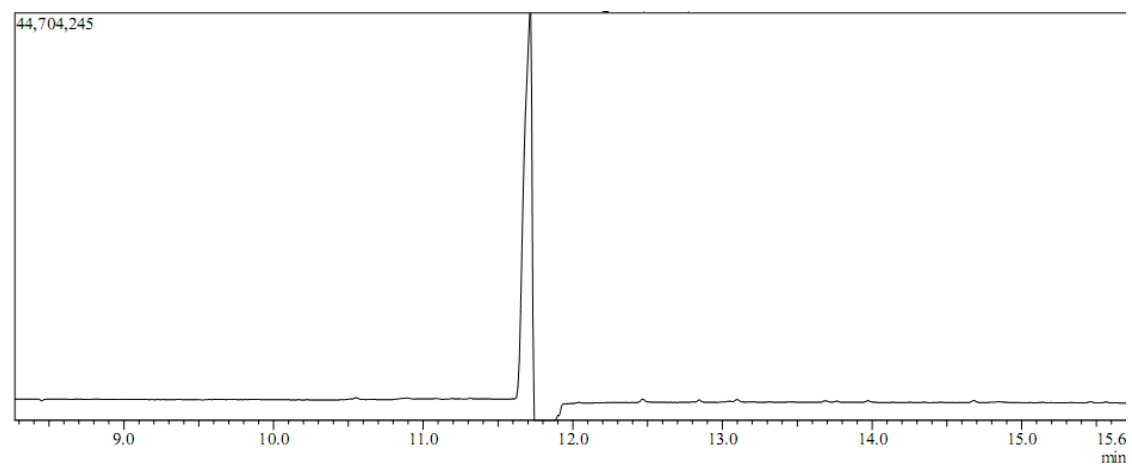

Figure 4: D-limonene GC-MS profile.

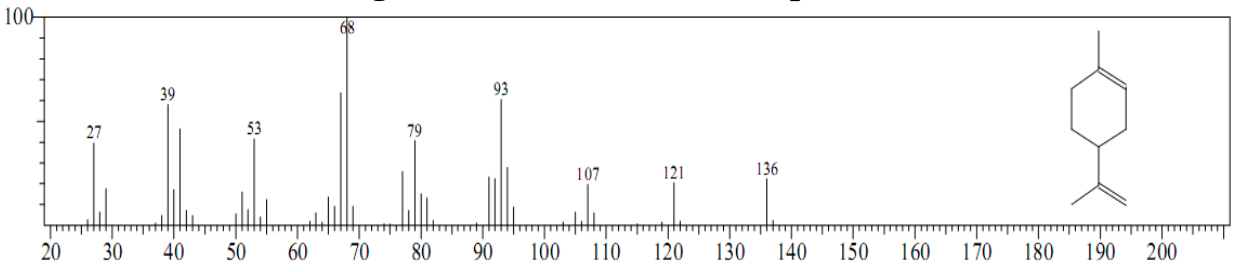

Figure 5: D-limonene GC-MS profile.

In present study three microorganisms were used for the estimation of the antimicrobial activity, $P$. aeruginosa, $S$. aureus and L. monocytogens. It was observed that 'Solarino Moro' and 'Sanguinello' were active against L. monocytogenes. 'Valencia' hexanic extract was not found active against all microorganisms ${ }^{15}$. Mass spectra were obtained from extract analysis in order to get fast and reliable identification of these species. For the confirm identification of specific metabolites, Tandem MS was utilized. For natural product analysis, HPTLC/DESIMS imaging is relatively fast and versatile and effective technique as many ions can be observed by the means of direct infusion ESI-MS. Information of component structures can be obtained by the means of MS/MS technique, thus reveals the presence of any bioactive components. In phytochemistry, detection and estimation of pharmacologically active components can be done through DESI-MS imaging ${ }^{16}$. The chromatographic analyses of the essential oil of $C$. aurantium have shown 14 components: $\beta$-pinene, $\beta$ mircene, 3 -carene, $D$-limonene, $\alpha$-pinene, cis- $\beta$ ocimene, $\gamma$-terpinene, $\beta$-linalol, $\alpha$-terpineol, nerill acetate, linalil acetate, lavandulol acetate, geraniol acetate and $\alpha$-bisabolene. The major compound identified in the oil was D-limonene and $\beta$-pinene. The chromatographic profile and the spectrometric results where the components were identified using the GCSolution software are below. The chemical characterization of D-limonene from C. aurantium using GC-MS has made possible to properly identify the component. The chromatographic profile and mass spectrum obtained using the GC Solution software are shown in Figure 1 to Figure 5. Recently, spices having different Phytochemicals have attracted many researchers to treat different life threatening diseases. Many nutraceutical substances are considered efficient for the treatment of cancer, thus strategies are working to treat such malignancy by nutraceuticals. In this way, the spices may play an important role. Some bioactive substances obtained from the spices have antioxidant activities that may increase free radicals scavenging ability at the cellular level thus improving many metabolic syndromes. There are many compounds obtained from spices that have chemotherapeutic potential against various malignancies like curcumin, limonene. Promising compounds including curcumin and curcuminoids (turmeric), limonene (cardamom), safranal, crocetin, $\alpha$ - and $\beta$-pinene, limonene, quercetin, allicin, gingerol, zingiberone, eugenol, crocin, zingiberene ${ }^{17}$.

Table 2: Body measures in centimeters.

\begin{tabular}{|c|c|c|c|c|}
\hline & Animal & $\begin{array}{c}\text { Lifespam } \\
\text { (days) }\end{array}$ & Initial & Final \\
\hline \multirow{6}{*}{ ن롤 } & $\mathrm{C} 1$ & 28 & 9.53 & 17.78 \\
\hline & $\mathrm{C} 2$ & 28 & 8.90 & 13.85 \\
\hline & C3 & 28 & 13.12 & 20.35 \\
\hline & $\mathrm{C} 4$ & 28 & 8.89 & 7.27 \\
\hline & C5 & 28 & 6.87 & 10.07 \\
\hline & C6 & 28 & 8.59 & 10.69 \\
\hline \multirow{6}{*}{ 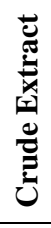 } & $\mathrm{C} 1$ & 28 & 8.63 & 9.34 \\
\hline & $\mathrm{C} 2$ & 28 & 19.22 & 22.24 \\
\hline & $\mathrm{C} 3$ & 28 & 10.01 & 13.19 \\
\hline & $\mathrm{C} 4$ & 28 & 7.25 & 10.69 \\
\hline & C5 & 28 & 8.04 & 7.16 \\
\hline & C6 & 28 & 11.03 & 18.66 \\
\hline \multirow{6}{*}{ 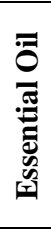 } & $\mathrm{C} 1$ & 28 & 7.05 & - \\
\hline & $\mathrm{C} 2$ & 28 & 8.16 & 10.34 \\
\hline & $\mathrm{C} 3$ & 28 & 5.78 & 6.95 \\
\hline & $\mathrm{C} 4$ & 28 & 16.88 & 22.68 \\
\hline & $\mathrm{C} 5$ & 28 & 4.75 & 13.57 \\
\hline & C6 & 28 & 21.93 & 21.505 \\
\hline \multirow{6}{*}{ 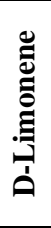 } & $\mathrm{C} 1$ & 28 & 17.44 & 15.26 \\
\hline & $\mathrm{C} 2$ & 28 & 10.61 & 12.62 \\
\hline & $\mathrm{C} 3$ & 28 & 11.59 & 18.56 \\
\hline & $\mathrm{C} 4$ & 28 & 9.76 & 7.44 \\
\hline & C5 & 28 & 11.01 & 11.37 \\
\hline & C6 & 28 & 11.17 & 5.35 \\
\hline
\end{tabular}

D-limonene is low toxic, and is tested in mice and rats for carcinogenicity. However in humans, low toxicity observed after single and repeated dose up to $1 \mathrm{yr}^{18}$. It increases the renal tubular tumors incidences in rats and mice (both gender) and there was no evidence of any tumor. 
Table 3: Hemogram performed after euthanasia.

\begin{tabular}{|c|c|c|c|c|c|c|c|c|c|}
\hline & Animal & Lc & Hc & Hb & $\mathbf{H t}$ & Plt & Neut & Linfo & Mono \\
\hline \multirow{6}{*}{ 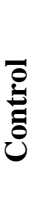 } & $\mathrm{C} 1$ & 4.3 & 10.05 & 15.3 & 44.7 & 672 & 0.56 & 3.77 & 0.05 \\
\hline & $\mathrm{C} 2$ & 3.9 & 10.42 & 17.1 & 48.4 & 661 & 0.54 & 3.34 & 0.01 \\
\hline & C3 & 3.7 & 9.46 & 15.5 & 44.0 & 609 & 0.62 & 4.70 & 0.06 \\
\hline & $\mathrm{C} 4$ & 3.9 & 9.34 & 16.5 & 45.3 & 643 & 0.56 & 4.37 & 0.02 \\
\hline & C5 & 4.1 & 9.53 & 15.4 & 44.8 & 646 & 0.51 & 3.82 & 0.00 \\
\hline & C6 & 3.7 & 10.22 & 16.2 & 48.8 & 576 & 0.49 & 4.54 & 0.03 \\
\hline \multirow{6}{*}{ 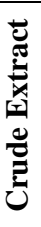 } & $\mathrm{C} 1$ & 2.2 & 9.55 & 15.5 & 44.6 & 633 & 0.13 & 3.68 & 0.01 \\
\hline & $\mathrm{C} 2$ & 2.1 & 9.23 & 15.1 & 42.6 & 641 & 0.14 & 3.12 & 0.01 \\
\hline & $\mathrm{C} 3$ & 1.8 & 9.03 & 14.9 & 43.6 & 650 & 0.16 & 3.46 & 0.01 \\
\hline & $\mathrm{C} 4$ & 2.2 & 9.08 & 15.2 & 43.1 & 675 & 0.08 & 3.08 & 0.00 \\
\hline & $\mathrm{C} 5$ & 2.3 & 9.96 & 15.8 & 46.0 & 689 & 0.11 & 3.43 & 0.01 \\
\hline & C6 & 2.4 & 9.31 & 15.0 & 43.5 & 672 & 0.29 & 3.31 & 0.04 \\
\hline \multirow{6}{*}{ 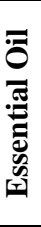 } & $\mathrm{C} 1$ & 1.8 & 9.41 & 15.8 & 44.4 & 689 & 0.14 & 2.26 & 0.00 \\
\hline & $\mathrm{C} 2$ & 2.1 & 9.85 & 15.4 & 44.9 & 719 & 0.10 & 2.01 & 0.00 \\
\hline & $\mathrm{C} 3$ & 2.4 & 9.80 & 15.6 & 45.8 & 693 & 0.11 & 2.24 & 0.00 \\
\hline & $\mathrm{C} 4$ & 2.3 & 9.74 & 15.2 & 43.9 & 698 & 0.14 & 2.33 & 0.01 \\
\hline & C5 & 2.7 & 8.93 & 14.7 & 42.7 & 657 & 0.18 & 2.32 & 0.03 \\
\hline & C6 & 2.4 & 9.29 & 14.9 & 44.1 & 693 & 0.17 & 2.48 & 0.02 \\
\hline \multirow{6}{*}{ 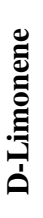 } & $\mathrm{C} 1$ & 1.9 & 9.12 & 14.9 & 45.6 & 684 & 0.14 & 2.66 & 0.02 \\
\hline & $\mathrm{C} 2$ & 1.9 & 9.71 & 14.6 & 45.7 & 644 & 0.13 & 2.72 & 0.02 \\
\hline & C3 & 2.5 & 10.00 & 15.2 & 46.0 & 659 & 0.19 & 3.02 & 0.04 \\
\hline & C4 & 2.3 & 9.32 & 15.6 & 44.7 & 599 & 0.18 & 2.85 & 0.01 \\
\hline & C5 & 2.1 & 10.29 & 16.1 & 47.5 & 703 & 0.17 & 2.51 & 0.00 \\
\hline & C6 & 3.8 & 9.12 & 15.4 & 45.4 & 617 & 0.14 & 2.63 & 0.01 \\
\hline
\end{tabular}

Lc (leukocytes); Hc (red blood cells); Hb (hemoglobin); Ht (hematocrit); Plt (platelets); Neut (neutrophils); Lymphocytes and Mono (monocytes).

Further study describe that D-limonene does not produce any nephrotoxic, mutagenic, and carcinogenic effects on human. As D-limonene is cholesterol solvent thus it dissolve cholesterol-containing gallstones. Furthermore it has gastric acid neutralizing efficiency, thus favor normal peristalsis, and used in heartburn and gastroesophageal reflux. It has chemotherapeutic potential in different types of cancers. Phase I clinical trial has shown partial response in breast cancer treatment, and disease stability in 3 patients having colorectal cancer ${ }^{19}$. The animals were weighed on analytical balance at the beginning and at the end of the experiment in order to identify possible abnormalities. The data distribution was analyzed using the ShapiroWilk test. The correlation of weight between moments in the groups was analyzed using the Spearman correlation test was used. The Kruskall-Wallis test was used to analyze the difference between weights in the initial and final moments between the groups. The level of confidence was $5 \%$ and the software used was Stata11.0. No significant differences were observed in all analyzes on body weight. In the hemogram, the red and white blood series were evaluated, and the statistical analysis was performed for each blood parameter. The cells identified with (-) indicate loss of the animal during the experiment, making it impossible to collect blood. Control group in general, was having higher levels of lymphocytes, neutrophils, leukocytes and monocytes as compared to the treatment groups. Data was analyzed by the means of Analysis of Variance (ANOVA), and by comparison test of Dunnett averages, however $95 \%$ confidence and statistical difference was not possible to observe. The Neutrophil/Lymphocyte Ratio (RLL) was evaluated and we could verify that, on average, the RLL of the control group is higher than that of the treatment groups, and that the ratio of the group that received extract is higher than that of the group receiving Dlimonene. However, this difference was not considered statistically significant by ANOVA statistical methods followed by Dunnet's means comparison test at $95 \%$ confidence level. The tumor growth was evaluated measuring the tumor weight in an analytical scale. The survival analysis was performed after the death of the animals. The control group has presented tumors weighing $2.89 \pm 0.34 \mathrm{~g}$. All treated groups and control groups differs significantly $(P<0.05)$. In comparison to the control, the treatment with crude extract $(0.61 \pm 0.14 \mathrm{~g})$ was found to be impressive in reducing the tumor. Furthermore, the groups treated with the essential oil (rich in limonene) have presented a significant difference from the control group but not among them. The treatment with D-limonene has shown the best result, with a weigh about $0.19 \pm 0.09 \mathrm{~g}$. Citrus bergamia (A.K.A. bergamot) has shown the potential to increase autophagy that was triggered due to rapamycin and serum starvation. Such findings show that mechanism is mTOR independent. On the other hand it does not affect two mTOR downstream targets (ULK1 and p70 (S6K) phosphorylation). Moreover, the active major constituents for these effects, Dlimonene and linalyl acetate, were also tested. Result indicates D-limonene is responsible for LC3II levels increase and p62 levels decrease ${ }^{20}$. Dlimonene epoxide had been tested for analgesic and anti-inflammatory activities. It inhibits release as well as inflammatory mediator's activities, reduces vascular permeability and migration of neutrophils. Analgesic assays, shows analgesic-dependent effects of the opioid system $^{21}$. D-limonene leads to apoptotic cell death by the suppression of viability of LS174T cells. This leads to activation of caspase- 3 and -9 and cleavage of PARP. During treatment with D-limonene increase in Bax protein and cytosol cytochrome $\mathrm{c}$ from 
mitochondria take place. Also decrease in bcl-2 protein is observed during treatment. The levels of $\mathrm{p}-\mathrm{GSK}-3 \beta$, and $\mathrm{p}$-Akt also gets reduced. These results indicate induction of apoptosis by the D-limonene due to the suppression of PI3K/Akt pathway and mitochondrial death $^{22}$. The essential oil of Citrus sinensis induce apoptosis and inhibit proliferation of colon cancer cells. Colon cancer cell's immunoblotting is due to dose-dependent induction of $\mathrm{Bax} / \mathrm{Bcl}_{2}$. Also there is inhibition of vascular endothelial growth factor. Furthermore inhibition of in vitro tube formation in human umbilical vein endothelial cells confirm the antiangiogenic activity essential oil $^{23}$. On a lymphoma cell D-limonene exert antiproliferative effects, this leads to increase in the nitric oxide levels by the means of induction of cell apoptosis in small concentration. In high concentrations, it has inhibited the farnesylation of proteins and $\mathrm{O}_{2}^{-}$production ${ }^{24}$.

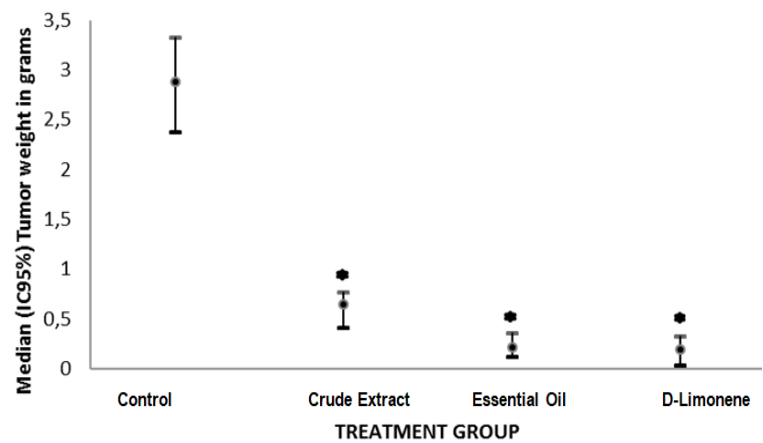

Figure 6: Inhibitory effect of crude extract, Dlimonene and essential oil of $C$. aurantium against Ehrlich ascites carcinoma.

Considering the data above, the use results present in this study are in agreement with the literature about Dlimonene and its potential as an anticancer drug or precursor (like limonene epoxide). This compound shows several mechanistic approach, related both to enzyme or genetic regulation, with high potential of obtention and no environment degradation since it is a waste product from orange crops and low cost.

\section{CONCLUSION}

It has been concluded that the essential oil and extract (crude) of Citrus aurantium, L. (Rutaceae) can become therapeutic agents because they have anti-tumor activity with no toxicity to the blood cells and have low cost of production. Moreover, the use of D-limonene as a precursor for new medicines using semi synthetic approaches. The chromatographic and spectrometric analyzes indicated the presence of other components in smaller amounts in the essential oil, what suggests that they could have a synergic activity to the D-limonene. Further studies are necessary, so they can be used in the treatment of neoplasia in humans.

\section{AUTHOR'S CONTRIBUTION}

Concept and design was of Fabio Ferreira Perazzo. Data acquisition (biological) was done by Kleber Rene da Silva and Pascalle Souza Rocha, while Data acquisition (Chemistry) was done by Luiz Elidio
Gregório and Marcio Adriano Andreo. Product isolation and characterization (D-Limonene) was performed by Renato Farina Menegon, Biochemical Assays was done by Davi Feder. Critical Revision was carried out by Fernando Luiz Affonso Fonseca.

\section{ACKNOWLEDGEMENTS}

The authors extend their thanks and appreciation to the UNIFESP, Diadema, SP, Brazil to provide necessary facilities for this work.

\section{CONFLICT OF INTEREST}

No conflict of interest associated with this work.

\section{REFERENCES}

1. Hafidh RR, Hyssein SZ, MalAlla MQ. Abdulamir AS, Bakar FA. A high-throughoutput quantitative expression analysis of cancer-related genes in human HepG2 cells in response to Limonene, a potential anticancer agent. Current Canc Drug Targ 2018; 18(8):807-815. https://doi.org/10.2174/1568009617666171114144236

2. Yang C, Chen H, Chen H, Zhong B, Luo X, Chun J. Antioxidant and anticancer activities of essential oil from gannan navel orane peel. Molecules 2017; 22(8):1391. https://doi.org/10.3390/molecules22081391

3. Prabuseenivasan S, Jayakumar M, Ignacimuthu S. In vitro antibacterial activity of some plant essential oils. BMC Complement Alt Med 2006' 6(1): 39-44. https://doi.org/10.1186/1472-6882-6-39

4. Shojaei S, Kiumarsi A, Moghadam AR, et al. Perillyl alcohol (monoterpene alcohol), limonene. Enzymes 2014; 36:7-32.

https://doi.org/10.1016/B978-0-12-802215-3.00002-1

5. Crowel PL. Prevention and therapy of cancer by dietary monoterpenes. J Nutrition 1999; 129:775-778. https://orcid.org/10.1093/jn/129.3.775S

6. Hata T, Sakaguchi I, Mori M, Ikeda N. Induction of apoptosis by citrus paradise essential oil in human leukemic (HL-60) cells. In Vivo 2003; 17:553-559. PMID: 14758720

7. Reddy BS, Wang CX, Samaha H, Lubert R, Steel VE. Chemoprevention of colon carcinogenesis by dietary perillyl alcohol. Cancer Res; 1997: 57:420-425.PMID: 9012468

8. Miyazawa M, Shindo M, Shimada S. Metabolism of (+)and (-)-limonenes to respective carveols and perillyl alcohols by CYP2C9 and CYP2C19 in human liver microsomes. Drug Metab Dispos 2002; 30(5): 602-7. https://doi.org/10.1016/10.1124/dmd.30.5.602

9. Da Fonseca, Simão CO, Lins M, et al. Efficacy of monoterpene perillyl alcohol upon survival rate of patients with recurrent glioblastoma. J Cancer Res Clin Oncol 2011; 137(2):287-93. https://doi.org/10.1007/s00432-010-0873-0

10. de Saldanha da Gama Fischer J, Carvalho PC, da Fonseca, $\mathrm{CO}$, et al. Chemo-resistant protein expression pattern of glioblastoma cells (A172) to perillyl alcohol. J Proteome Res 2011; 10(1):153-60. https://doi.org/10.1021/pr100677g

11. Mohamed AA, El-Emary GA, Ali HF. Influence of some citrus essential oils on cell viability, glutathione-Stransferase and lipid peroxidation in Ehrlich ascites carcinoma cells. J American Sci; 2010: 6(10).

12. Adams RP. Identification of Essential Oil Components by Gas Chromatography/Mass Spectroscopy; Allured Publ. Corp., Carol Stream, IL 1995:499.

13. Sokal RR, Rohlf FJ. Freeman WH, editor. Biometry. San Francisco; 1995: 175-205, 404-86.

14. Karlson J, Borg-karlson AK, Unelius R, et al. Inhibition of tumor cell growth by monoterpenes in vitro: evidence of a 
Ras-independent mechanism of action. Anticancer Drugs 1996; 7(4):422-9.

https://doi.org/10.1097/00001813-199606000-00008

15. Geraci A, Di Stefano, Di Martino V, et al. Essential oil components of orange peels and antimicrobial activity. Nat Prod Res 2017; 31(6):653-659.

https://doi.org/10.1080/14786419.2016.1219860

16. Bagatela BS, Lopes AP, Cabral EC, Perazzo FF, Ifa DR. High-performance thin-layer chromatography/desorption electrospray ionization mass spectrometry imaging of the crude extract from the peels of Citrus aurantium L. (Rutaceae). Rapid Commun Mass Spectrom 2015; 30; 29(16):1530-4.

https://doi.org/10.1002/rcm.7246

17. Butt MS, Naz A, Sultan MT, Qayyum MM. Antioncogenic perspectives of spices/herbs: A comprehensive review. EXCLI J 2013; 17(12):1043-65. PMID: 27092039

18. Tsuda H, Ohshima Y, Nomoto H, et al. Cancer Prevention by Natural Compounds. Drug Metab Pharmacokinet 2004; 19(4):245 - 63. https://doi.org/10.2133/dmpk.19.245

19. Sun JD. Limonene: safety and clinical applications. Altern Med Rev 2007; 12(3):259-64. PMID: 18072821

20. Russo R, Cassiano MG, Adornetto A, et al. Role of Dlimonene in autophagy induced by bergamot essential oil in SH-SY5Y neuroblastoma cells. PLoS One 2014; 24;9(11). https://doi.org/10.1371/journal.pone.0113682

21. Almeida AA, Silva RO, de Brito, et al. Physiopharmacological investigations about the antiinflammatory and antinociceptive efficacy of (+)Limonene epoxide. Inflammation 2017; 40(2):511-522. https://doi.org/10.1007/s10753-016-0496-y

22. Jia SS, Xi GP, Zhang M, et al. Induction of apoptosis by D-limonene is mediated by inactivation of Akt in LS174T human colon cancer cells. Oncol Rep 2013; 29(1):349-54. https://doi.org/10.3892/or.2012.2093

23. Murthy C, Jayaprakasha GK, Patil BS. D-limonene rich volatile oil from blood oranges inhibit anbgiogenesis, metastasis and cell death in human colon câncer cells. Life Sci 2012; 5;91(11-12):429-439.

https://doi.org/10.1016/j.lfs.2012.08.016

24. Manuele MG, Barreiro Arcos ML, Davicino R, et al. Limonene exerts antiproliferative effects and increases nitric oxide levels on a lymphoma cell line by dual mechanism of the ERK pathway: relationship with oxidative stress. Cancer Invest 2010; 28(2):135-45. https://doi.org/10.3109/07357900903179583 